\title{
Opportunities and Challenges in The Use of an External Interprofessional Reviewing Body in a Curricular Review Process in a Doctor of Physical Therapy Curriculum
}

Jill FitzGerald

Saint Louis University, jfitzg21@slu.edu

Kelly Hawthorne

Saint Louis University, hawthokd@slu.edu

Follow this and additional works at: https://nsuworks.nova.edu/ijahsp

Part of the Medicine and Health Sciences Commons

\section{Recommended Citation}

FitzGerald J, Hawthorne K. Opportunities and Challenges in The Use of an External Interprofessional Reviewing Body in a Curricular Review Process in a Doctor of Physical Therapy Curriculum. The Internet Journal of Allied Health Sciences and Practice. 2016 Jan 01;14(1), Article 2.

This Manuscript is brought to you for free and open access by the College of Health Care Sciences at NSUWorks. It has been accepted for inclusion in Internet Journal of Allied Health Sciences and Practice by an authorized editor of NSUWorks. For more information, please contact nsuworks@nova.edu. 


\title{
Opportunities and Challenges in The Use of an External Interprofessional Reviewing Body in a Curricular Review Process in a Doctor of Physical Therapy Curriculum
}

\begin{abstract}
Purpose: The purpose of this article is to describe the opportunities and challenges of a curricular review process in an entry-level doctor of physical therapy geriatric curriculum. The curricular review process utilized an external interprofessional reviewing body, in conjunction with an established internal curricular reviewing body, to determine inclusion of Essential Competencies in order to prepare students for best clinical practice in the care of the older adult. Method: The methodology of our curricular review process included both internal and external reviewing bodies but the intent of this article is to highlight how the review process was implemented including an external interprofessional reviewing body. The internal reviewing body involved two faculty members with expertise in geriatrics, the Program Curriculum Committee members, and the faculty members within the entry-level doctor of physical therapy program. The external reviewing body was comprised of the 2012-2014 members of the Faculty Development Collaborative Program in Geriatrics (FDCPG), a national interprofessional learning community representing multiple disciplines involved in the care of older adults. Results: The outcomes of including an external interprofessional reviewing body in the geriatric curricular review process were: the FDCPG justified the need for the review of the Essential Competencies, deemed their role as important in healthcare education, and reported a greater understanding of the role of physical therapists as part of an interprofessional healthcare team. The Program Curriculum Committee created a policy for consideration of other published competencies, including a recommendation for "other necessary consultation" based on our use of an external reviewing body, noting its value. The outcomes of the overall curricular review process included: 53/61 Essential Competencies were identified as already in the curriculum and the remaining 8/61 Essential Competencies were added. Conclusions and Recommendations: The addition of an external interprofessional reviewing body to an already established internal reviewing body within the geriatric curricular review process in an entry-level doctor of physical therapy program produced a curriculum that will hopefully prepare students for best clinical practice in the care of the older adult. This comprehensive curricular review process involved opportunities and challenges yet still can be used across multiple disciplines, across multiple curricular structures, and is in line with the current state of healthcare practice.
\end{abstract}

\section{Author Bio(s)}

- Jill FitzGerald PT, DPT, GCS, CSCS, is an assistant professor in the Dept of Physical Therapy and Athletic Training at St. Louis university. She teaches in the classroom, and is also part of the Clinical Education Team. She is an APTA Credentialed Clinical Instructor, Credentialed Advanced Clinical Instructor. Dr. FitzGerald is also a Board Certified Geriatric Specialist, Certified Exercise Expert for the Aging Adult and a Certified Strength and Conditioning Specialist. Dr. FitzGerald has clinical experience in geriatrics, mainly in subacute, outpatient and wellness settings.

- Kelly Hawthorne PT, DPT, GCS, is an assistant professor in the Dept of Physical Therapy and Athletic Training at St. Louis University. She earned her BS in Exercise Science, Master of Physical Therapy, and transitional Doctor of Physical Therapy degrees from Saint Louis University. She is an ABPTS Certified Specialist in Geriatric Physical Therapy and practices weekly with the geriatric patient population. She is an APTA Credentialed Instructor, Advanced Clinical Instructor, and Credentialed Clinical Instructor Trainer. She is a member 
of the Clinical Education Team.

This manuscript is available in Internet Journal of Allied Health Sciences and Practice: https://nsuworks.nova.edu/ijahsp/vol14/iss1/2 


\title{
TIJAHSP \\ The Internet Joưnal of Allied Health Sciences and Practice
}

Dedicated to allied health professional practice and education

Vol. 14 No. 1 ISSN 1540-580X

\section{Opportunities and Challenges in The Use of an External Interprofessional Reviewing Body in a Curricular Review Process in a Doctor of Physical Therapy Curriculum}

\author{
Jill FitzGerald, PT, DPT, GCS, CSCS \\ Kelly Hawthorne, PT, DPT, GCS \\ Saint Louis University \\ United States
}

\begin{abstract}
Purpose: The purpose of this article is to describe the opportunities and challenges of a curricular review process in an entrylevel doctor of physical therapy geriatric curriculum. The curricular review process utilized an external interprofessional reviewing body, in conjunction with an established internal curricular reviewing body, to determine inclusion of Essential Competencies in order to prepare students for best clinical practice in the care of the older adult. Method: The methodology of our curricular review process included both internal and external reviewing bodies but the intent of this article is to highlight how the review process was implemented including an external interprofessional reviewing body. The internal reviewing body involved two faculty members with expertise in geriatrics, the Program Curriculum Committee members, and the faculty members within the entry-level doctor of physical therapy program. The external reviewing body was comprised of the 2012-2014 members of the Faculty Development Collaborative Program in Geriatrics (FDCPG), a national interprofessional learning community representing multiple disciplines involved in the care of older adults. Results: The outcomes of including an external interprofessional reviewing body in the geriatric curricular review process were: the FDCPG justified the need for the review of the Essential Competencies, deemed their role as important in healthcare education, and reported a greater understanding of the role of physical therapists as part of an interprofessional healthcare team. The Program Curriculum Committee created a policy for consideration of other published competencies, including a recommendation for "other necessary consultation" based on our use of an external reviewing body, noting its value. The outcomes of the overall curricular review process included: 53/61 Essential Competencies were identified as already in the curriculum and the remaining 8/61 Essential Competencies were added. Conclusions and Recommendations: The addition of an external interprofessional reviewing body to an already established internal reviewing body within the geriatric curricular review process in an entry-level doctor of physical therapy program produced a curriculum that will hopefully prepare students for best clinical practice in the care of the older adult. This comprehensive curricular review process involved opportunities and challenges yet still can be used across multiple disciplines, across multiple curricular structures, and is in line with the current state of healthcare practice.
\end{abstract}

\section{BACKGROUND}

The number of older adults (over 65 years of age) will almost double between 2005 and 20301 By $2030,20 \%$ of the United States population will be older adults; those over 85 years of age are the fastest growing segment of that category. ${ }^{2}$ Not only is the number of older adults increasing, but the number of older adults living with one or more complex medical issues is on the rise. Additionally, the support systems, polypharmacy, and financial burdens associated with care of the older adult reinforce the need for interprofessional, patient-centered, team-based healthcare, in which all providers are competent to work with the older adult population. A recent practice analysis of physical therapy estimates that $40 \%$ of patient care is delivered to older adults. ${ }^{3}$

Concerns over medical errors and quality of care, including morbidity and mortality, demand health profession education be patient-centered, interprofessional, and team-based. ${ }^{4}$ The individualized knowledge and experience of each team member builds a strong foundation of quality patient care and is cost-effective. ${ }^{5}$ The American Geriatric Society highlights ten healthcare 
professions (e.g. medicine, nursing, occupational therapy, physical therapy, social work) that regularly care for older adults, and the Institute of Medicine calls on those professionals to improve their educational curricula and training for care of older adults. ${ }^{1,6}$ As healthcare education evolves, not only is the Institute of Medicine calling for improvements in older adult educational curriculum, but national organizations recommend that specific geriatric competencies for the entry-level healthcare provider inform curricula. Physical therapy, nursing, and medicine are among the many professions that have specific published curricular competencies for the entry-level provider.6-11 The Academy of Geriatric Physical Therapy, a section of the American Physical Therapy Association (APTA), developed and published the "Essential Competencies in the Care of Older Adults at the Completion of the Entry-Level Physical Therapist Professional Program of Study" (Domains and 'sub competencies' referred to as Essential Competencies; see (http://geriatricspt.org/pdfs/AGPT-PTA-Essential-Competencies.pdf). ${ }^{11}$ Although entry-level physical therapist education programs are not mandated by the Commission on Accreditation in Physical Therapy Education (CAPTE) to meet these Essential Competencies, faculty may wish to consider these Essential Competencies when developing or revising entry-level geriatric physical therapy curriculum. In addition to internal reviews that are already conducted to make program decisions, faculty may also wish to consider including an interprofessional reviewing body, within the curricular review process, to mimic best clinical practice in the care of the older adult. ${ }^{12,13}$

External reviewers are widely used within the worlds of both academia and healthcare. Within education, external reviewers, such as program advisory committees and national discipline-specific accrediting bodies, are used to ensure best educational practices within a specific scope of practice. Submissions of manuscripts to journals routinely undergo an external expert review prior to determining acceptance and publication. Within healthcare, institutions are routinely visited by external organizations, such as Joint Commission on Accreditation of Healthcare Organizations, or state authorities, to ensure safety and quality service to the community.

The literature regarding the external review practices common in academia and healthcare is limited and often contradictory. The 2008 Cochrane Review dissected the peer review process for grant funded research and concluded that there is little to no correlation between grant funded peer reviewed research and the quality of such research. ${ }^{14}$ In contrast, Goodman et al concluded that peer review did improve the quality of medical research, specifically the generalizability of the research. ${ }^{15}$ The Internal Committee of Medical Journal Editors stated that external peer review, for manuscript submission to journals, is widely debated but does provide an unbiased opinion different from those familiar with the science, and therefore increased the quality of the research. ${ }^{16}$ In higher education, accreditation (and re-accreditation) includes an external review component. Dodd concluded that the external reviewing body holds the institution accountable for achieving set goals and objectives. ${ }^{17}$ Similarly, Shah described the external reviewing body as effective for quality improvement, and highlighted the external reviewing body's role in forcing the internal reviewing body to accurately self-assess, therefore strengthening the entire review process. ${ }^{18}$ Within healthcare systems, the use of external bodies aims to ensure quality patient care to the community. Walshe et al concluded, after interviewing multiple team members within the National Health Services in England, that external reviews are intended for quality improvement, although the best usage of the external review component to be most effective is still unknown. ${ }^{19}$

The composition of the external reviewing body is also important to the review process. Utilization of an interprofessional team models best practice in the care of the older adult patient and therefore should be paralleled in the geriatric curricular review process. ${ }^{20,21}$ An interprofessional external reviewing body also prompts healthy debate and informs decisions regarding curriculum. ${ }^{22}$

After reviewing evidence, considering common practice in academia and healthcare to include an external body, and the intent for a curricular review process to ensure comprehensive geriatric physical therapy education, consideration of an interprofessional external reviewing body, in combination with an internal reviewing body, appears warranted. No evidence is noted to include an interprofessional external reviewing body in geriatric healthcare curricular review processes. Therefore, the purpose of this article is to describe the opportunities and challenges of a curricular review process which utilizes an external interprofessional reviewing body, in conjunction with an established internal curricular reviewing body, to determine inclusion of Essential Competencies in an entry-level Doctor of Physical Therapy (DPT) geriatric curriculum in order to prepare students for best clinical practice in the care of the older adult.

\section{METHODS}

The methodology of our curricular review process included both internal and external reviewing bodies. It is not the intent of this article to describe the internal review process as most programs likely have such mechanisms already in place. Additionally, it is not the intent to describe Saint Louis University's entry-level DPT geriatric curriculum in depth, but to highlight how the review process was implemented to include an external interprofessional reviewing body and the opportunities and challenges found during this process. Geriatric content in entry-level physical therapy programs can be taught over a number of courses

(C) The Internet Journal of Allied Health Sciences and Practice, 2016 
(integrated) or in specific courses dedicated to geriatrics (segregated). In the process described below, the geriatric content is integrated into the last 3 years of a 6 year DPT curriculum.

\section{Curricular Review Process \\ Members of the Review Process}

The internal component of the curricular review process involved two faculty members with expertise in geriatrics, in this article referred to as the content experts. Both content experts are Board Certified Specialists in Geriatric Physical Therapy and both have over 10 years of clinical experience working with older adults. The content experts, the Program Curriculum Committee members, and the faculty within the Program in Physical Therapy, made up the established internal reviewing body. The external reviewing body was comprised of the 2012-2014 members of the Faculty Development Collaborative Program in Geriatrics (FDCPG). The FDCPG brought together a national interprofessional learning community composed of individuals representing multiple disciplines who are involved in the care of older adults (for example, administrators, nurses, physicians, physical therapists, researchers, and social workers). The FDCPG fostered rich discussion of knowledge and skills that allows for best practice of interprofessional patient-centered care of the older adult. The FDCPG is not affiliated with the Program in Physical Therapy. The interactions between the geriatric physical therapy content experts and the internal and external curricular reviewing bodies are described below.

\section{Integration of the Internal and External Reviewing Bodies}

The content experts initiated the curricular review process through a meeting with the Program Chair of the Program Curriculum Committee. The Essential Competencies were presented to the Chair and a request for time at the next Curriculum Committee meeting was made. One content expert then attended a Curriculum Committee meeting and discussed the Essential Competencies document and the importance of a review of the curriculum for the inclusion of these Essential Competencies. The Curriculum Committee members gained a better understanding of the Essential Competencies at this meeting. The Curriculum Committee members, representing multiple content areas of the curriculum, identified which courses currently addressed the Essential Competencies. Along with the content experts, the extent to which the Essential Competencies were addressed was discussed. At the conclusion of this discussion (and throughout the process), the content experts made the final determination as to which Essential Competencies were already adequately covered in the current curriculum. As a result, 42/61 Essential Competencies were identified as appropriately addressed within the curriculum.

After the initial determination of what was currently covered through the internal review, the content experts initiated the first contact with FDCPG via webcam. The content experts requested feedback as to whether or not the Program should perform a thorough curricular review process for the inclusion of the remaining Essential Competencies. Because of the interprofessional nature of the Essential Competencies, and the interprofessional nature of the care for the older adult, the FDCPG unanimously recommended review of the DPT curriculum for the remaining Essential Competencies, validating the need for a full curricular review.

During an all-faculty meeting, the content experts reviewed the remaining 19 Essential Competencies with the faculty. A discussion occurred in which faculty identified which, if any, of the remaining 19 Essential Competencies were covered in their course(s). Six Essential Competencies were immediately identified. Faculty were given the task to specifically identify in which course(s) and specific course objectives, if any, the remaining 13 Essential Competencies were addressed. They were to report back at the next faculty meeting or to communicate individually with the content experts. After a second discussion, the faculty collectively identified three additional Essential Competencies that were appropriately addressed in the curriculum. Therefore, 10 Essential Competencies remained unidentified in the DPT curriculum.

The second interaction between the content experts and the FDCPG occurred via webcam and the remaining 10 Essential Competencies were presented to the FDCPG. The objective of this communication was to obtain an external opinion regarding the importance of these remaining Essential Competencies relative to the interprofessional care of the older adult. After focused discussion on these 10 remaining Essential Competencies between various healthcare professionals (geriatricians, gerontologists, geriatrics occupational therapists, geriatric nurses, and geriatric social workers) across various settings throughout the United States, all members of the FDCPG, strongly advised that all 10 remaining Essential Competencies be considered for inclusion in the DPT curriculum. The FDCPG stated these remaining Essential Competencies were needed in a geriatric PT curriculum. These remaining 10 Essential Competencies reflected many of the FDCPG's expectations of practicing PTs working with older adults as part of an interprofessional healthcare team.

Given the external interprofessional reviewing body's recommendations to further consider the 10 remaining Essential Competencies, the content experts reviewed individual DPT course syllabi to determine if there were any additional course

(c) The Internet Journal of Allied Health Sciences and Practice, 2016 
objectives that related to the remaining 10 Essential Competencies that were not already brought forth by faculty. Based on this review, individual meetings with the content experts and selected members of the faculty were scheduled to determine if one or more of the remaining 10 Essential Competencies were addressed in his or her course(s). This individualized approach ensured a comprehensive review of all course content for inclusion of the 10 remaining Essential Competencies. After in-depth discussions between the content experts and individual faculty members regarding the 10 Essential Competencies and specific course content, none of the remaining 10 Essential Competencies were identified within the core PT curriculum. The content experts discovered two of the remaining Essential Competencies within the Interprofessional Education Curriculum, a required series of courses within the PT curriculum although not taught exclusively by PT faculty, resulting in eight Essential Competencies unidentified within the PT curriculum.

In the end, the content experts deemed the eight remaining Essential Competencies integral to the curriculum and presented them to the Curriculum Committee as such. The Curriculum Committee unanimously agreed the eight remaining Essential Competencies were crucial to the DPT curriculum. The Curriculum Committee then designated courses for inclusion of each remaining Essential Competency. The Curriculum Committee discussed the additional content with the Course Coordinators of each of these courses and how they correlated with current course specific objectives.

Table 1: Eight Essential Competencies added to the DPT Curriculum ${ }^{11}$

1. Define chemical restraints as they relate to physical therapist practice.

2. Identify regulatory agencies responsible for monitoring and enforcing restraint policies across health care settings.

3. Cite evidence that validates the impact of physical and chemical restraint use on the restrained individual, the restrained individual's caregiver(s), and society.

4. Describe and advocate alternatives to chemical restraint use that are safe and least restrictive (e.g., positioning devices, enabling devices, environmental adaptation, caregiver/care worker supervision or intervention).

5. Differentiate between depression, delirium, and dementia based on presentation and related conditions; and refer as appropriate.

6. Identify options for least restrictive environment that maximizes physical functional ability and independence.

7. Educate caregiver in accessing and using resources for optimal functioning in least restrictive manner.

8. Identify resources available to facilitate community-dwelling older adults' ability to live independently (e.g., meal delivery, home care resources, social services, electronic alert devices, community support groups, transportation services, home modifications, adaptive equipment).

The final communication with the FDCPG via webcam reviewed the whole curricular review process and final incorporation of the Essential Competencies in the PT curriculum. During this meeting, the content experts received feedback on the opportunities and challenges of this process and discussed the generalizability of the process across various healthcare professions and curricula. Consensus from the FDCPG was that the recommended competencies should be considered in developing geriatric curriculum in healthcare professions, and that an external interprofessional reviewing body is highly informative and likely necessary in this type of curricular review process.

\section{Inclusion of External Interprofessional Reviewing Body}

The outcomes of including an external interprofessional reviewing body in the geriatric curricular review process were: 1) The FDCPG justified the need for the review of the Essential Competencies in the Care of Older Adults at the Completion of the Entry-level Physical Therapist Professional Program of Study in the DPT curriculum. 2) The FDCPG deemed their role in the curricular review process as important and necessary in healthcare education curricular reviews. 3) The FDCPG reported a greater understanding of the role and responsibilities physical therapists have as part of an interprofessional healthcare team. 4) The Program Curriculum Committee created a policy/procedure for consideration of other sections of the APTA published competencies and how they are considered within the curriculum (Appendix A). This policy included a recommendation for "other necessary consultation" based on our use of an external reviewing body, noting its value.

\section{Overall Curricular Review Process}

The outcomes of the overall curricular review process included: 1) $53 / 61$ (87\%) Essential Competencies were identified as already in the curriculum. 2) The 8/61 (13\%) remaining Essential Competencies were added to the DPT curriculum. 3) The DPT faculty voiced a greater understanding of how geriatric content is integrated throughout the curriculum and their role in the geriatric content in DPT curriculum. 


\section{CONCLUSIONS}

The inclusion of an external interprofessional reviewing body to current internal curricular review processes provided a more indepth review and understanding of how geriatric content is integrated throughout the curriculum. Solomon and Gedde's22 curricular review of healthcare ethics and Diwan and Wertheimer's ${ }^{20}$ curricular review of geriatric content in social work curriculum involved external stakeholders in the curricular review process that resulted in the opportunity for each stakeholder to understand and embrace each discipline's specific responsibilities in geriatric healthcare. Similar to our process and outcome, the inclusion of an external reviewing body contributed to a comprehensive quality curriculum in a given healthcare field. 20,22 The FDCPG acted as an unbiased, yet widely educated in geriatrics, resource for the PT content experts. This supports the Internal Committee of Medical Journal Editor's findings that an unbiased opinion from those familiar with the science increases quality. ${ }^{16}$ The curricular review process including both internal and external reviewing bodies also produced a geriatric physical therapy curriculum that included all Essential Competencies recommended by the APTA's Academy of Geriatric Physical Therapy. ${ }^{11}$ The complexity of the geriatric patient, and rise in number of geriatric patients anticipated in the near future, warrants patient-centered interprofessional quality care be taught in order to be delivered. ${ }^{2}$ Usage of an external reviewing body, composed of geriatric healthcare experts, in the curricular review process supports best geriatric patient-care. ${ }^{12,13}$ Congruent with Goodman et al, not only did the FDCPG believe their role was critical to curricular review success, but the internal physical therapy faculty believe this process, with the inclusion of "any other needed consultation" improved the quality of geriatric education delivered to students..$^{15}$ While limited, the best available evidence supports the use of an external reviewing body in a curricular review process and acknowledged common practice in academia and healthcare. This produced a comprehensive geriatric curriculum for entry-level physical therapy students including all Essential Competencies and an internal and external reviewing body with a greater understanding of curricular needs to support the interprofessional delivery of geriatric healthcare. We anticipate the need to assess the long-term outcomes of these curricular changes.

\section{Opportunities and Challenges}

Our process encompassed multiple opportunities and challenges. One major factor that positively influenced our process was our academic community and its strong focus on interprofessional collaboration in education. Administrators at our university encouraged us to build a relationship with the already established FDCPG. In time, the group, whose mission was to encourage and foster interprofessional geriatric practice, became a great resource and integral part of our curricular review process. In addition, this group had pre-determined meeting times throughout the year in which we were invited to utilize for our curricular review. This consistently held us accountable to our process and external reviewing body. Furthermore, the ancillary departments at our academic institution, such as the Information Technology Department, enabled communication with the FDCPG through easily accessible technologies available to all participating bodies of our review process. In addition, our professional organization, the APTA, had recently published the Essential Competencies, giving us already reviewed and published guidelines to utilize in our review of the DPT curriculum. These numerous opportunities negated many of the potential challenges. Common challenges, such as time, cost, and availability of technology were minimized secondary to the opportunities previously mentioned. While individual time commitments across various faculty responsibilities were shifted, this challenge was minimal and easily overcome. One anticipated challenge was the need for concise presentation of our process and needed participation of the FDCPG during our allotted times. This challenge was easily surmounted through concentrated effort to pre-plan and determine outcomes for each encounter.

\section{CRITICAL SUCCESS FACTORS/RECOMMENDATIONS}

Despite limitations and long-term outcomes that still need to be assessed, we believe this process is generalizable to other healthcare education programs. This curricular review process was developed for a DPT Program that has geriatric content integrated across multiple courses, using physical therapy professional entry-level geriatric Essential Competencies; however, this process can be applied to other physical therapy competencies published by other sections of the APTA (e.g. Clinical Electrophysiology and Wound Management, Neurology, Pediatrics, and Women's Health).23-26 Likewise, other healthcare professions (i.e. nursing and medicine) have similar recommended competencies; therefore, this curricular review process could apply to their professional curricula. 6-10 The key internal and external components of the curricular review process are replicable. The internal component, faculty with content expertise willing to oversee the process, faculty with knowledge of curriculum, and the collective faculty, are likely present in all healthcare educational programs. While we had the advantage of a FDCPG, the external component does not require a national interprofessional group; local interprofessional experts could serve in this role as well. The use of an external reviewing body within a curricular review process can be added to an already established internal review process, can be used across multiple disciplines and across multiple curricular structures, and is in line with the current state of healthcare practice.

When considering utilization of and external interprofessional body within a curricular review process there are critical factors to consider for success of this process: 1) Consider your already established interprofessional resources and further develop one of

(C) The Internet Journal of Allied Health Sciences and Practice, 2016 
your relationships to utilize in this process. 2) Plan the entire process including scheduling meetings, deadlines, and goals for each step. 3) Partner with other invested individual(s) to lead this process, ensuring there is no interruption to the curricular review plan. 4) Share this process and its intentions with other departmental faculty, administration, and vital department committees to foster development of a supportive environment for curricular review and potential curricular change. A common goal-oriented academic program and healthcare community is vital because this process is the critical link between interprofessional healthcare and a curriculum that prepares students for best clinical practice.

\section{REFERENCES}

1. Institute of Medicine (US) Committee on the Future Health Care Workerforce for Older Americans. Retooling for an Aging America: Building the Health Care Workforce. Washington (DC): National Academic Press (US); 2008. [PMID 25009893]

2. Saxon SV. A Guide for the Helping Professions: Physical Change \& Aging, 5e. New York, NY: Springer Publishing Company; 2010.

3. Bradley K, Caramagno J, Water S, Koch A. Analysis of Practice for the Physical Therapy Profession: Entry-Level Physical Therapists by the Federation of State Boards of Physical Therapy. 2011; https://fsbpt.org/download/PA2011_PTFinalReport20111109.pdf. Accessed December 17, 2014.

4. Schmitt MH, Gilbert JH, Brandt BF, Weinstein RS. The coming of age for interprofessional education and practice. Am J Med. 2013;126(4):284-8. [PMID 23415053]

5. Mitchell P. Core Principles \& Values of Effective Team-Based Healthcare. Institute of Medicine of the National Academics. 2012

6. American Geriatrics Society. Partnership for Health in Aging: Multidisciplinary Competencies in the Care of Older Adults at the Completion of the Entry-Level Health Professional Degree. http://www.americangeriatrics.org/files/documents/health_care_pros/PHA_Multidisc_Competencies.pdf. Accessed April 14, 2013.

7. Bardach SH, Rowles GD. Geriatric education in the health professions: are we making progress? Gerontologist. 2012;52(5):607-18. [PMID 22394495]

8. Eleazer GP, McRae T, Knebl J, et al. Core competencies for the care of older patients: recommendations of the american Ggeriatrics society. Acad Med. 2000;75(3):252-5. [PMID 10724313]

9. American Association of Colleges of Nursing. The Essentials of Baccalaureate Education for Professional Nursing Practice. Washington, DC: American Association of Colleges of Nursing 2008.

10. American Association of Colleges of Nursing \& The Hartford Geriatric Nursing Initiative. Nurse Practitioner and Clinical Nurse Specialist Competencies for Older Adult Care. 2004

11. Section on Geriatrics American Physical Therapy Association. Essential Competencies in the Care of Older Adults at the Completion of the Entry-level Physical Therapist Professional Program of Study. GeriNotes. 2011;18(6):27-30.

12. Clark PG. Values in health care professional socialization: implications for geriatric education in interdisciplinary teamwork. Gerontologist. 1997;37(4):441-51. [PMID 9279032]

13. Goldberg LR, Koontz JS, Rogers N, Brickell J. Considering accreditation in gerontology: the importance of interprofessional collaborative competencies to ensure quality health care for older adults. Gerontology \& Geratrics Education. 2012;33(1):95-110. [PMID 22289069]

14. Demicheli V, Di Pietrantonj C. Peer review for improving the quality of grant applications. Cochrane Databse of Systematic Reviews. 2007(2).[PMID 17443627]

15. Goodman SN, Berlin J, Fletcher SW, Fletcher RH. Manuscript quality before and after peer review and editing at Annals of Internal Medicine. Annals of Internal Medicine. 1994;121(1):11-21. [PMID 8198342]

16. Editors ICoMJ. Uniform Requirements for Manuscripts Submitted to Biomedical Journals: Writing and Editing for Biomedical Publication. 2008; http://www.icmje.org/recommendations/archives/2008_urm.pdf. Accessed September 17, 2014.

17. Dodd AH. Accreditation as a catalyst for institutional effectiveness. New Directions for Institutionsal Research. 2004(123).

18. Shah M. Ten years of external quality audit in Australia: evaluating its effectiveness and success. Assessment \& Evaluation in Higher Education. 2012;37(6):761-72.

19. Walshe K, Wallace L, Freeman T, Lathem L, Spurgeon P. The external review of quality improvement in health care organizations: a qualitive study. International Journal for Quality Health Care. 2001;13(5):367-74. [PMID 11669564]

20. Diwan SP, Wertheimer MRP. Aging services or services to the aging? Focus of a university-community curriculum development partnership to increase awareness of aging issues in social work practice. Journal of Gerontological Social Work. 2007;50(1/2):187-204. [PMID 18032307]

21. Dorfman LT, Murty SA, Ingram JG, Li H. Faculty and community partners in gerontological curriculum enrichment.

(c) The Internet Journal of Allied Health Sciences and Practice, 2016 
Educational Gerontology. 2008;34:1087-104.

22. Solomon P, Geddes E. A systematic process for content review in a problem-based learning curriculum. Med Teach. 2001;23(6):556-60. [PMID 12098474]

23. Association SoCEaWMAPT. APTA's Section on Clinical Electrophysiology and Wound Management Guide for Integumentary/Wound Management Content in Professional Physical Therapist Education. 2014; http://www.aptascewm.org/wp-content/uploads/2014/07/APTA-SCEWM-Integ-Curriculum-Recommendations-2014.pdf. Accessed December 12, 2014.

24. Section on Neurology APTA. Neurologic Entry-level Curricular Content Integrated with a Normative Model of Physical Therapist Professional Education. 2011; http://www.neuropt.org/docs/default-document-library/2011_neurologic_entrylevel_curriculum_guidelines7E676FEAFF3D.pdf?sfvrsn=4. Accessed December 12, 2014.

25. Rapport M, Furze J, Martin K, et al. Essential competencies in entry-level pediatric physical therapy education. Pediatric Physical Therapy. 2014;26(1):7-18. [PMID 24356312]

26. Section on Women's Health APTA. Section On Women's Health, APTA, Guidelines for Women's Health Content in Professional Physical Therapist Education. 2005; file:///C:/Users/fitzg21/Downloads/ContentGuidelinesforEntryLevelPhysicalTherapyEducation.pdf. Accessed December 12, 2014. 
Appendix A

\section{Review Process for APTA Section Competencies in DPT Curriculum}

Assumptions:

1. APTA BOD are responsible for Standards of Practice

2. APTA-Section Competencies are recommendations on best practices for a particular specialty area. Steps:

1. Faculty members who are section members or specialists bring section-approved entry-level practice competencies to the attention of the Program Curriculum Committee members.

a. Upon notification, the Curriculum Committee will refer the competencies to the appropriate content area work-group(s). The work group(s) is (are) then responsible for assessing whether the curriculum is meeting the competencies as published.

b. As needed, additional feedback can be gathered from the entire faculty during DPT Curriculum discussion period in a monthly faculty meeting.

c. The results of the work-group analysis should be brought back to the Curriculum Committee members to review where the curriculum is and is not meeting the competencies.

d. The assigned work groups should prepare a summary report for Curriculum Committee. In this report, recommendations should be made for potential additions or deletions of curricular content

2. Based on this report and any other needed consultation, members of Curriculum Committee determine what content must be added/deleted from curriculum based on trends in the profession, Standards of Practice and recommendations of the work group(s).

a. Depending on the scope of the content, appropriate faculty give feedback on the logical course(s) in which to include content

3. Curriculum Committee Chair will post the content on the Excel Spreadsheet - Content Area Assessment Curriculum Changes under Cross-Curricular Tab for tracking purposes. 